\title{
POR QUE SÓ OS POBRES FAZEM GREVE?
}

¿POR QUÉ SÓLO LOS POBRES HACEN PARO?

WHY ONLY THE POOR STRIKE?

POURQUOI SEULS LES PAUVRES FONT LA GRÈVE?

Cristian Cipriani ${ }^{1}$

VIEIRA PINTO, Álvaro. Por que os ricos não fazem greve? Coleção

Cadernos do Povo Brasileiro, v. 4. Rio de Janeiro: Editora Civilização Brasileira, 1962. $118 \mathrm{p}$.

Álvaro Borges Vieira Pinto foi um filósofo brasileiro pouco (re) conhecido no Brasil. Nascido em Campos dos Goytacazes - RJ, no dia 11 de novembro de 1909, e falecido no dia 11 de junho de 1987, de infarto, na cidade

${ }^{1}$ Pontifícia Universidade Católica do Rio Grande do Sul (PUCRS), Porto Alegre/RS, Brasil. 
do Rio de Janeiro, antes de seguir carreira como filósofo, catedrático da Faculdade Nacional de Filosofia e diretor do Iseb², formou-se, em 1932, no curso de medicina da Faculdade Nacional de Medicina (RJ). Durante o exílio no Chile, decorrência do golpe militar de 1964, o filósofo produziu, a princípio como conteúdo para um curso de verão, um dos maiores sucessos editorais da educação brasileira, a saber: "Sete Lições sobre a educação de jovens e adultos (1982)3". Nesse ínterim, dedicou-se também à leitura e "correção" dos originais da Pedagogia do Oprimido de Paulo Freire e à escrita de outros três livros. Após seu retorno ao Brasil, em dezembro de 1968, isolou-se, até o dia da sua morte, em seu apartamento em Copacabana, dedicando seu tempo para escrever obras (algumas ainda inéditas e desaparecidas) e fazer traduções de textos clássicos para o português - sendo a última atividade uma forma de conseguir dinheiro à manutenção de sua existência.

Isso posto, cabe apontar que a pergunta que confere título a este escrito é, na verdade, distinta do título do texto de Álvaro Vieira Pinto, apresentado no volume 4 da Coleção Cadernos do Povo Brasileiro, apenas na aparência, pois, em essência, tende ao mesmo objetivo, a saber: apontar que somente os "pobres" podem fazer greve, porque somente os "pobres", na concepção sóciofilosófica alvariana, trabalham. Ou seja, "no país capitalista, especialmente no de economia subdesenvolvida, o trabalho compete, por definição às massas assalariadas que, por seu modo de existência, são chamadas de 'pobres' " (VIEIRA PINTO, 1962, p. 101).

Em termos gerais, pode-se aventar que Álvaro Vieira Pinto intenta explorar nesse volume, a partir do fenômeno da greve, as concepções de trabalho e de capital, bem como examinar os possíveis efeitos das paredes

\footnotetext{
2 O Instituto Superior de Estudos Brasileiros, celebrizado na sigla Iseb, começou a funcionar em 1956, com os cursos sendo ministrados no auditório do Ministério da Educação e Cultura, enquanto o prédio em que funcionaria efetivamente, a partir de 1957, na rua das Palmeiras, n. 55, em Botafogo, passava pelos reparos destinados a adequá-lo às necessidades daquela instituição. Para saber mais, conferir: Sodré (1978).

3 Uma das possíveis explicações para o sucesso editorial da obra de um autor pouco (re) conhecido no Brasil, deve-se ao fato de ser "prefaciada" e ter sua publicação idealizada, em certa medida, por Dermeval Saviani.
} 
grevistas para a passagem, da sociedade brasileira, à consciência crítica. Ademais, cabe assinalar, antes de prosseguir efetivamente explorando a escrita alvariana, que o contexto em que o filósofo sistematizou a obra em questão era propício para tanto, pois, além da experiência bolchevique que ainda ressoava no Brasil, do pacto comercial entre a potência do leste europeu e a ilha pósrevolucionária de Cuba, o Brasil experimentava, por um lado, em nível infra estrutural, os benefícios da crescente industrialização e, por outro, inúmeras e progressivas paradas operárias 4 . Foi valendo-se de tais fatos e de uma “metabolização" à tupiniquim dos conceitos marxistas e existencialista que o autor organiza seu pensando na pequena obra, distribuindo o texto, além da introdução, em 6 capítulos, intitulados da seguinte maneira: 1) "Que são os ‘ricos’?”; 2) “Que é greve?”; 3) “Por que há 'ricos'?”; 4) “Por que há greves?”; 5) “Por que não há greves de 'ricos’?” e; 6) “Por que só os ‘pobres' fazem greves?”.

Assim, na introdução do caderno número 4, Vieira Pinto lança-se na busca de um conceito de ser humano. Ao criticar e rejeitar as concepções que esquadrinham a essência humana apenas em nível metafísico, isto é, de forma abstrata e ideal, o filósofo e educador brasileiro apresenta o ser humano como um ser social. O caráter social do ser humano é, segundo o autor, consequência do modo particular como tais seres se relacionam com a natureza no provimento das condições indispensáveis para a manutenção da vida, por efeito das necessidades impostas pela execução dessa relação vital com o mundo natural, ou em outras palavras, como resultado do trabalho. Isso significa que, para o pensador, o trabalho realizado pelo ser humano sobre o mundo exterior, com a finalidade de produzir o que não está imediatamente dado para a sua existência, não pode ser desenvolvido de modo individual, ou seja, agindo cada trabalhador independente dos demais. O êxito da ação laboral está condicionado a associação dos indivíduos no cumprimento de operação conjunta que se leva a cabo para sustentar a vida. Por isso, para Vieira Pinto, o trabalho, para ser viável, impõe o surgimento de vínculos entre os seres

\footnotetext{
4 Para uma análise detalhada e dados completos sobre as greves ocorridas no país, consultar: Mattos (2004).
} 
humanos, ou em outros termos, "a produção dos bens, que é a sua finalidade, assume obrigatoriamente caráter social” (VIEIRA PINTO, 1962, p. 10). Nesse sentido, é possível afirmar que, para o autor brasileiro, o ser humano só existe mediante as relações sociais e, em última instância, achando-se envolvido por determinado sistema de relações produtivas, cuja realidade não depende de sua vontade.

No primeiro capítulo, isto é, “Que são os 'ricos'?”, Álvaro Vieira Pinto traz à luz quem são os "ricos" e por que se tornaram ricos. Partindo de uma análise complexa que vai da sociedade primitiva organizada comunitariamente até as atuais sociedades capitalistas, o filósofo do terceiro mundo infere que "só há ricos porque existem condições sociais que permitem a espoliação do trabalho coletivo efetuado por todo o povo, representado pela acumulação e apropriação dos benefícios desse trabalho nas mãos de alguns afortunados" (VIEIRA PINTO, 1962, p. 16). Por isso, lembra o pensador, que nos regimes sociais onde não há efetiva propriedade social dos meios de produção, onde o povo in totum não é possuidor dos instrumentos de trabalho, instala-se o desnível social, isto é, a riqueza cada vez mais excessiva de alguns ao lado da pobreza, igualmente maior, da imensa maioria do povo. Entretanto, assim como apreendem Karl Marx e Friedrich Engels (1962) em Le manifeste du Parti Communiste, Vieira Pinto expõe que a exploração progressiva do trabalhador pela classe dirigente, a repressão violenta - material e ideológica - da consciência emergente e a necessidade capitalista de constante aprimoramento das ferramentas, tornam-se húmus para a consciência crítica das massas.

Em vista disso, Vieira Pinto traz à tona, no segundo capítulo - isto é: "Que é a greve?" - a parede grevista como uma das expressões mais sensíveis da luta social entre os assalariados e seus empregadores na contemporaneidade. Com intuito de melhor esclarecer o conceito, o pensador apresenta tal fato social sob duas miradas, a saber: a) o aspecto externo e; b) o essencial. No que diz respeito à ocorrência visível, "a greve se define como decisão coletiva, total ou parcial, de uma categoria profissional, ou em casos mais raros, de todos os 
assalariados, de abandonar o trabalho por determinado motivo de caráter econômico ou político". (VIEIRA PINTO, 1962, p. 32). Ou seja, a greve, na aparência, se manifesta como pura e simples voluntária recusa a trabalhar. Já no que se refere à sua essência, a greve consiste "[...] no trabalhar para si, sob aparência do não-trabalhar". Na análise de Álvaro Vieira Pinto, no regime capitalista, o trabalhador entrega para um não trabalhador, para outro, isto é, para o capitalista, os frutos totais do seu trabalho e só recebe o correspondente a uma fração mínima, necessária para mantê-lo vivo como um ser não humano de trabalho. Nessa lógica, ao entrar em greve, o trabalhador força o capitalista a lhe deixar maior parte do seu trabalho para si. Isto é, "o que o trabalhador está pleiteando é o aumento para si do trabalho que faz para os outros. Quer ampliar (até chegar um dia à totalidade) a parte para si do seu trabalho. Numa palavra, não quer continuar a trabalhar para outro”. Assim sendo, a greve, em essência, revela ao trabalhador que ele é sujeito livre, ou melhor, livre criador da existência por intermédio de seu trabalho. Não obstante, em última instância, a ação paredista constitui-se em critério social para diferenciar quem trabalha de quem não trabalha.

Os existenciais, para si e para o outro, utilizados como categorias complementares, pelo autor brasileiro, à categoria trabalho, direcionam o texto para o terceiro capítulo, assim como corroboram na reflexão da questão que o intitula, qual seja: “Por que há 'ricos'?”. Nessa direção, cabe apontar que, se somente o "pobre" pode fazer greve, pois, somente ele trabalha, isso significa que só há "ricos" porque, em uma sociedade dividida em classes, a riqueza produzida pelos trabalhadores torna-se para o outro, isto é, para o senhor da propriedade privada. Tal afirmação tem dupla consequência para a resolução da questão que dá título ao capítulo três, a saber: a) Só há "rico" porque o "trabalho" do "rico" consiste em acumular, isto é, capitalizar o trabalho não pago ao trabalhador; b) Só há "rico" porque as massas trabalhadoras não têm ainda consciência do significado do trabalho e não conhecem as causas da situação desumana que se encontram. Por isso, a divisão da sociedade entre "ricos" e "pobres", terminará, de acordo com Vieira Pinto, “[...] quando o povo, 
em sua totalidade, se apropriar dos produtos que seu esforço físico e intelectual, cria” (VIEIRA PINTO, 1962, p. 67).

Dando sequência à obra, no capítulo seguinte, Álvaro Vieira Pinto se propõe a refletir face a seguinte pergunta: “Por que há greve?”. Tal como faz no segundo capítulo, o filósofo e educador assinala, a fim de tratar a demanda proposta, dois axiomas, quais sejam: a) o de natureza ingênua e; b) o de natureza crítica. Referindo-se à primeira instância, Vieira Pinto caracteriza como ingênuas as interpretações que buscam estabelecer uma relação causal entre a ocorrência da greve e um fato ou situação precedentes imediatas, a exemplo de uma paralisação em decorrência de reivindicação salarial. Já a interpretação crítica, dotada das categorias dialéticas, traz à luz a parede grevista, como fato social, apresentando duas facetas, ou seja: uma face externa e uma essência interna. Segundo o filósofo do terceiro mundo, só é possível compreender a greve, em sua plena realidade, ao abarcar os dois aspectos ao mesmo tempo, apreendendo-os na independência mútua que os conecta. Assim, no aspecto externo, para a consciência crítica, a greve tonar-se índice - no sentido semiótico - de uma realidade latente. Em outras palavras, só é possível a greve nas formações sociais onde se apura a alienação do trabalho e a não totalidade do trabalho para si. Já no aspecto essencial, a greve, mesmo quando não alcança os objetivos imediatos, serve para fazer avançar a consciência de classe da massa trabalhadora. Nessa lógica, a paralisação grevista serve como prelúdio para a revolução. Aliás, segundo Álvaro Vieira Pinto, não há distinção real entre greve e revolução, pois, ambas têm o mesmo objetivo, a saber: alterar as relações de produção existentes, buscando por cabo ao trabalho alienado, ou seja, ambas intentam instaurar o regime universal do trabalho para si. O que as difere é a faceta externa, temporal. Enquanto a greve é uma revolução de curta duração, a revolução é uma greve definitiva.

Retomando parte do já tratado, no capítulo cinco, o pensador aborda a questão: "Porque não há greves de 'ricos'?”. Segundo o autor, duas são as razões: a primeira, porque os "ricos" não podem fazê-la, visto que, conforme já 
explicitado, não trabalham. Isto é, mesmo ocupando todo seu tempo com atividades em que se consomem, tais afazeres não são considerados trabalho, porque é o serviço exigido deles para manutenção, defesa e alargamento do capital que possuem. Dessa forma, falar em greve do capitalista torna-se uma impossibilidade social e econômica; a segunda razão da não existência de greves de "ricos", está no motivo de que não precisam fazê-la, pois, de acordo com Vieira Pinto, acreditam que os trabalhadores fazem para eles. Em outros termos, a classe dirigente busca no expediente grevista a justificativa para aumentar os preços e, sobretudo, incrementar a pressão política que conseguem exercer, a seu favor, sobre as cúpulas governamentais5. Todavia, faz-se importante ressaltar, assim como faz Vieira Pinto, que a greve, por ser uma arma dos trabalhadores contra a classe dirigente, sempre é eficaz, no sentido de fazer avançar a consciência crítica do povo que labuta em regime de exploração.

Para findar o Caderno número 4 do Povo Brasileiro, o autor constrói seu argumento na interface da pergunta que intitula este texto. Com outras palavras, mas reiterando o já exposto, Vieira Pinto entende que, em um país de economia subdesenvolvida como o Brasil, o trabalhador só faz greve porque é "pobre", entretanto, só é "pobre" porque é trabalhador. Nesse ponto do texto, faz-se importante mencionar que a "pobreza" não representa, nos escritos alvarianos, um conceito sociológico e nem moral, mas sim um modo existencial do trabalhador na sociedade capitalista. Isto é, tal "complemento", mostra que os atuais "pobres" são apenas servidores do capital, que este se gerou pela acumulação do trabalho não pago, e que tais condições são passíveis de mudança e desaparecimento assim que o mundo abandonar o sistema explorador. Por isso, aponta o pensador que a greve é a escola de sociologia e de história do trabalhador, pois, é nesse "que fazer" que a consciência avança e, o ser humano que labuta, passa a compreender os mecanismos que regem a sociedade em que vive.

5 Não é difícil, ao ler essas linhas, de lembrar da intervenção patronal na "Greve dos Caminhoneiros" do ano de 2018. Para uma análise completa sobre tal acontecimento, conferir: Filgueiras; Krein (2019). 
Quase ao "apagar das luzes", ou melhor, no "cessar da tinta", o professor Vieira Pinto interpela um caso particular de greve, qual seja: a dos estudantes. Segundo o pensador, a greve dos estudantes, além de ser autêntica, encontra sua essência na existência, pois, tais agentes não são trabalhadores em ato, mas sim em preparo. Ou seja, a greve de estudantes é possível existencialmente porque estão se comportando antecipadamente como trabalhadores, dado que o empenho nas lutas sociais lhes é prescrito pela situação de pretendentes a um trabalho que almejam mais humano e fecundo que o atual ${ }^{6}$.

Em suma, ao aproximarmo-nos do livreto "Porque os 'ricos' não fazem greve?”, não só nos cercamos de um momento importante da história do Brasil, como também avizinhamo-nos de nosso próprio tempo, pois, apesar da distância temporal entre a edição do texto e nosso tempo histórico, muitas das ideias e das categorias sistematizadas por Vieira Pinto ainda servem como "lentes" de leitura e análise à existência contemporânea na América Latina. Ao reportar essa coetaneidade, não quero situar o autor como ser à frente do seu tempo, mas apenas sinalizar que as condições objetivas que possibilitaram a emersão de tal análise, isto é, a realidade de exploração do trabalhador em um país capitalista subdesenvolvido, mesmo em uma era de capitalismo invisível, seguem ainda vigentes em nossos dias. Por isso, creio que resgatar os textos alvarianos pode servir, ao pesquisador em educação, para apreender o conturbado momento político e econômico vivido em todo continente latino americano.

\section{REFERÊNCIAS}

FERREIRA, Sofia Rodrigues. Juventudes secundaristas, educação, cultura e política: o fenômeno das ocupações de 2016 em Porto Alegre/RS. 2017. Dissertação (Mestrado) - Pontifícia Universidade Católica do Rio Grande

\footnotetext{
${ }^{6}$ A modalidade de greve estudantil apresentada por Vieira Pinto alcança sua mais autêntica forma nas mobilizações estudantis, ocorridas no ano de 2016, no Brasil. Para saber mais, verificar: Ferreira (2017).
} 
do Sul (PUCRS), Escola de Humanidades, Programa de Pós-Graduação em Educação, Porto Alegre/RS, 2017.

FILGUEIRAS, Vitor Araújo; KREIN, José Dari. A raiz da greve dos caminhoneiros e a regulação do trabalho. Instituto Humanitas Unisinos, 29 maio 2018. Disponível em: http://www.ihu.unisinos.br/78-noticias/579431a-raiz-da-greve-dos-caminhoneiros-e-a-regulacao-do-trabalho.

MARX, Karl; ENGELS, Friedrich. Le manifeste du Parti communiste. Paris: Union Générale D’Édititions, 1962. 187 p.

MATTOS, Marcelo Badaró. Greves, sindicatos e repressão policial no Rio de Janeiro (1954-1964). Revista brasileira de história, São Paulo, v. 24, n. 47, 2004 .

SODRÉ, Nelson Werneck. A verdade sobre o Iseb. Rio de Janeiro: Avenir Editora, 1978.

VIEIRA PINTO, Álvaro. Por que os ricos não fazem greve? Coleção Cadernos do Povo Brasileiro, v. 4. Rio de Janeiro: Editora Civilização Brasileira, 1962. $118 \mathrm{p}$.

CRISTIAN CIPRIANI é Bacharel em Comunicação Social e Mestre em Educação pela Universidade Comunitária da Região de Chapecó. Doutorando em Educação na Escola de Humanidades da Pontifícia Universidade Católica do Rio Grande do Sul (PUCRS). Membro da Rede de Estudos sobre Álvaro Vieira Pinto. Bolsista da Coordenação de Aperfeiçoamento de Pessoal de Nivel Superior - Brasil (Capes).

E-mail: cristiancipriani87@gmail.com

(D) http://orcid.org/0000-0001-8217-4538

Recebido em: 14 de novembro de 2018

Aprovado em: 06 de maio de 2019

Revista História da Educação - RHE

Associação Sul-Rio-Grandense de Pesquisadores em História da Educação - Asphe Artigo de acesso aberto distribuído nos termos de licença Creative Commons. 